\title{
Interethnic diversity of NAT2 polymorphisms in Brazilian admixed populations
}

\author{
Jhimmy Talbot ${ }^{1 \dagger}$, Luiz Alexandre V Magno ${ }^{1,2+}$, Cinthia VN Santana ${ }^{1 \dagger}$, Sandra MB Sousa ${ }^{1}$, Paulo RS Melo ${ }^{1}$, \\ Ronan X Correa', Giuliano Di Pietro ${ }^{1}$, Fabrício Rios-Santos ${ }^{1 *}$
}

\begin{abstract}
Background: N-acetyltransferase type 2 (Nat2) is a phase II drug- metabolizing enzyme that plays a key role in the bioactivation of aromatic and heterocyclic amines. Its relevance in drug metabolism and disease susceptibility remains a central theme for pharmacogenetic research, mainly because of its genetic variability among human populations. In fact, the evolutionary and ethnic-specific SNPs on the NAT2 gene remain a focus for the potential discoveries in personalized drug therapy and genetic markers of diseases. Despite the wide characterization of NAT2 SNPs frequency in established ethnic groups, little data are available for highly admixed populations. In this context, five common NAT2 SNPs (G191A, C481T, G590A, A803G and G857A) were investigated in a highly admixed population comprised of Afro-Brazilians, Whites, and Amerindians in northeastern Brazil. Thus, we sought to determine whether the distribution of NAT2 polymorphism is different among these three ethnic groups.
\end{abstract}

Results: Overall, there were no statistically significant differences in the distribution of NAT2 polymorphism when Afro-Brazilian and White groups were compared. Even the allele frequency of 191A, relatively common in African descendents, was not different between the Afro-Brazilian and White groups. However, allele and genotype frequencies of G590A were significantly higher in the Amerindian group than either in the Afro-Brazilian or White groups. Interestingly, a haplotype block between G590A and A803G was verified exclusively among Amerindians.

Conclusions: Our results indicate that ethnic admixture might contribute to a particular pattern of genetic diversity in the NAT2 gene and also offer new insights for the investigation of possible new NAT2 geneenvironment effects in admixed populations.

\section{Background}

Genetic functional polymorphisms of xenobiotic/drug metabolizing enzymes have been associated with pharmacotherapy response differences and disease risk susceptibility $[1,2]$. Special emphasis has been placed on a phase II metabolizing enzyme, $\mathrm{N}$-acetyltransferase type 2 (Nat2, EC 2.3.1.5), a milestone in the pharmacogenetics field as one of the first enzymes to be associated as a cause of interindividual variation in drug metabolism [3]. Nat2 catalyzes a transfer of an acetyl group from the cofactor acetyl-coenzyme A (acetyl-CoA) to the amine nitrogen atom of aromatic amines and hydrazines [4]. This enzyme is important in the aromatic and

\footnotetext{
* Correspondence: fabriciorios@yahoo.com

+ Contributed equally

'Universidade Estadual de Santa Cruz, Laboratório de Farmacogenômica e Epidemiologia Molecular (LAFEM), Ilhéus, Bahia, Brazil

Full list of author information is available at the end of the article
}

heterocyclic amine conjugating reaction, preventing their metabolic activation into electrophilic intermediates that could initiate DNA damage and potentially induce carcinogenic mutations [5]. Moreover, Nat2 plays a role in the metabolism of different hydrazine and arylamine drugs, such as isoniazid and dapsone, both used in the treatment of Mycobacterium spp. infections $[6,7]$.

The human NAT2 gene has an intronless open reading frame of 870 base pairs and is primarily expressed in the liver and intestines [8-10]. It has long been recognized that some single nucleotide polymorphisms (SNPs) in the NAT2 gene may change protein structure and/or stability and segregate in humans into "rapid", "intermediate" and "slow" acetylation phenotypes $[11,12]$. The effects of genetic polymorphism in the NAT2 gene on $\mathrm{N}$-acetylation activity led to investigations of NAT2 SNPs as a promising genetic marker for 
disease risk, drug response therapy and/or adverse reactions to drugs [13]. For example, slow acetylators are at increased risk of peripheral neuropathies and systemic lupus erythematosus due to hepatotoxicity to isoniazid treatment, hypersensibility reactions to sulphonamides and poor tolerance to sulfasalazine and dapsone [14]. Conversely, some authors demonstrated increased risk of myelotoxicity induced by amonafide in rapid acetylators, probably due to the production of higher levels of toxic metabolites from drugs [15].

If genetic factors underlie disease risk, the distribution of susceptibility alleles may be influenced by ethnic diversity [16]. Consistent with this question, several studies have shown that frequencies of NAT2 SNPs differ among established ethnic groups [17]. Although the characterization of the frequency of NAT2 SNPs has been established in some ethnic groups, it is still necessary to investigate the distribution of NAT2 SNPs in populations characterized by a high degree of admixture. Brazilian populations are of particular interest since it was historically originated by Caucasian settlers, descendents of African slaves, and by Amerindians [18-20]. In this context, we investigated the frequency of five common NAT2 SNPs (G191A, C481T, G590A, A803G and G857A; G191A) and haplotype structure in a highly admixed population in Northeastern Brazil.

\section{Methods}

\section{Subjects}

All 183 individuals included in the current study were residents in the Ilhéus area, healthy blood donors at São José Hospital (Ilhéus, Bahia, Brazil) and reported at least 3 familial generations resident in Northeastern Brazil. Volunteers were randomly selected during a 6-month period and classified by self-reported ancestry into AfroBrazilian, Amerindians (native Brazilian descendents of the Tupinamba tribe) or White. The Human Ethical Committee of Universidade Estadual de Santa Cruz approved the study and all volunteers gave their informed consent.

\section{Sample collection and genotyping}

Peripheral blood was collected and genomic DNA isolation was performed from white blood cells using the FlexiGene DNA Kit (Qiagen, Boston, USA). NAT2 genotypes were determined using a modification of a polymerase chain reaction (PCR)-restriction fragment length polymorphisms (RFLP) assay [21]. Genomic DNA (100 ng) amplification was carried out in a $25 \mu \mathrm{L}$-reaction volume containing $10 \mathrm{mmolL}^{-1}$ Tris- $\mathrm{HCl}$ (pH 8.3), 50 $\mathrm{mmolL}^{-1} \mathrm{KCl}, 1.5 \mathrm{mmolL}^{-1} \mathrm{MgCl}_{2}, 0.2 \mathrm{mmolL}^{-1}$ of each deoxynucleotide triphosphate (dNTP), $0.2 \mu \mathrm{molL}^{-1}$ of each oligonucleotide primer (Forward, 5'-GGCTATAAGAACTCTAGGAAC-3' and Reverse, 5' -AAGGGTT
TATTTTGTTCCTTATTCTAAAT-3'), and 1.25U of Platinum Taq DNA polymerase (Invitrogen, California, USA). Thermal cycling conditions for the PCR were as follows: $5 \mathrm{~min}$ at $94^{\circ} \mathrm{C}$, followed by 35 cycles of $94^{\circ} \mathrm{C}$ for $1 \mathrm{~min}, 55^{\circ} \mathrm{C}$ for $1 \mathrm{~min}$, and $72^{\circ} \mathrm{C}$ for $1 \mathrm{~min}$, with a final extension at $72^{\circ} \mathrm{C}$ for $5 \mathrm{~min}$.

Following amplification, genotyping was performed using a RFLP assay to detect five different NAT2 SNPs: G191A (rs1801279), C481T (rs1799929), G590A (rs1799930), A803G (rs1208) and G857A (rs1799931). In this assay, PCR products ( $895 \mathrm{bp}$ ) were digested separately with MspI, KpnI, TaqI, BamHI (Fermentas, Canada) and DdeI (New England Biolabs, USA) to detect a specific SNP (Table 1). All digestions were performed according to the manufacturer's recommendations. Digested PCR products were separated by electrophoresis on 2\% agarose gels (Pronadisa, Madrid, Spain) for MspI, KpnI and BamHI or $10 \%$ polyacrylamide gels for TaqI and DdeI (90-100 V for 120 min or 6 hours, respectively) with DNA molecular size markers (Invitrogen, California, USA). The amplified products were visualized with ethidium bromide staining under UV light.

\section{Statistical analysis}

Individual marker analysis comparing genetic and allelic frequencies among ethnic groups was performed using $\chi^{2}$ tests. Multiple logistic regression analysis to evaluate ethnic influences on the polymorphism frequency and genetic associations were carried out using the Statistical Package for the Social Sciences v.15.0 (Chicago, IL, USA) and UNPHASED v.3.0.13 [22], respectively. We used default settings of HAPLOVIEW v.4.1 software [23] to evaluate pairwise linkage disequilibrium (LD) between the five SNPs, genotype deviation from HardyWeinberg equilibrium (HWE) and for association between haplotypes defined by block in comparison groups [23]. For an accurate type I error, we performed 1,000 permutations in each procedure test to estimate the global significance of the observed differences. The test computes the significance by counting the number of ways the data can be permuted to determine how unusual an observed outcome is. All tests were twotailed and the $p$ level of significance retained was 0.05 .

\section{Results}

\section{Allelic and Genotypic Associations}

The sample was composed predominantly of AfroBrazilians (68.31\%), Whites (15.3\%) and Amerindians (16.39\%) (average age $34.3 \pm 10.2$ yrs, $71 \%$ males).

The allele and genotype frequencies of the NAT2 SNPs obtained from all individuals and in separate ethnic groups are summarized in Table 2. $481 T$ was the most frequent allele with $38.79 \%$ in the general 
Table 1 NAT2 SNPs used in this study

\begin{tabular}{|c|c|c|c|c|}
\hline SNPs & RFLP Enzyme & Aminoacid Substitution & Enzymatic Activity & Reference \\
\hline $\begin{array}{c}\text { G191A } \\
(\text { rs1801279) }\end{array}$ & Mspl & Arg64Gln & Reduced & {$[28,29]$} \\
\hline $\begin{array}{c}\text { C481T } \\
(\operatorname{rs} 1799929)\end{array}$ & Kpnl & - & Non-Altered & {$[28]$} \\
\hline $\begin{array}{c}\text { G590A } \\
(\text { rs1799930) }\end{array}$ & Taql & Arg197Gln & Reduced & {$[28]$} \\
\hline $\begin{array}{l}\text { A803G } \\
(r s 1208)\end{array}$ & Ddel & Lys268Arg & Non-Altered & {$[26]$} \\
\hline $\begin{array}{c}\text { G857A* } \\
(\text { rs 1799931) }\end{array}$ & $\mathrm{BamHI}$ & Gly286Gln & Reduced & {$[28,30,31]$} \\
\hline
\end{tabular}

These levels are referents to the presence of a single SNP and If there is not anyone SNP in the 2 gene copies. *Substrate dependent.

population $(33.9-43.3 \%)$ whereas the $191 \mathrm{~A}$ allele was less frequent in the three ethnic groups ranging from 5.0 and $10.7 \%$ ( $8.8 \%$ in total). No statistically significant differences were observed in the distribution of NAT2 polymorphisms when comparing Afro-Brazilian and
White groups (Table 2). However, allelic and genotypic frequencies of $6590 \mathrm{~A}$ polymorphism were significantly increased in Amerindians when compared with other ethnic groups and remained statistically different after multiple testing corrections (Table 2), and multiple

Table 2 Genotypic and allelic frequency of NAT2 gene in different ethnic groups

\begin{tabular}{|c|c|c|c|c|c|c|c|c|c|c|}
\hline $\begin{array}{l}\text { NAT2 } \\
\text { SNP }\end{array}$ & Total & Afro-Brazilians & $x^{2}$ & $p^{1}$ & Whites & $\chi^{2}$ & $p^{2}$ & Amerindians & $\chi^{2}$ & $p^{3}$ \\
\hline \multicolumn{11}{|l|}{ G191A } \\
\hline GG & 158 & 104 & & & 23 & & & 27 & & \\
\hline GA & 22 & 20 & 1.075 & 0.5842 & 4 & 1.781 & 0.4104 & 3 & 1.207 & 0.547 \\
\hline AA & 3 & 1 & & & 1 & & & 0 & & \\
\hline G & 28 & 228 & 0.202 & 0.6593 & 50 & 1.322 & 0.2471 & 57 & 0.942 & 0.3061 \\
\hline A & 338 & 22 & & & 6 & & & 3 & & \\
\hline \multicolumn{11}{|l|}{ C481T } \\
\hline $\mathrm{CC}$ & 72 & 41 & & & 11 & & & 12 & & \\
\hline$C T$ & 79 & 60 & 2.565 & 0.2774 & 15 & 4.836 & 0.089 & 10 & 2.36 & 0.3073 \\
\hline$\pi$ & 31 & 23 & & & 2 & & & 8 & & \\
\hline C & 223 & 142 & 1.466 & 0.2221 & 37 & 1.079 & 0.2982 & 34 & 0.007 & 0.9338 \\
\hline $\mathrm{T}$ & 141 & 106 & & & 19 & & & 26 & & \\
\hline \multicolumn{11}{|l|}{ G590A } \\
\hline GG & 92 & 77 & & & 19 & & & 10 & & \\
\hline GA & 67 & 46 & 1.298 & 0.5224 & 8 & 4.312 & 0.1158 & 14 & 9.943 & $0.0069^{b}$ \\
\hline AA & 24 & 2 & & & 1 & & & 6 & & \\
\hline G & 251 & 200 & 0.005 & 0.9405 & 46 & 4.661 & $0.0288^{a}$ & 34 & 8.4 & $0.0053^{c}$ \\
\hline A & 115 & 50 & & & 10 & & & 26 & & \\
\hline \multicolumn{11}{|l|}{ A803G } \\
\hline $\mathrm{AA}$ & 107 & 64 & & & 15 & & & 17 & & \\
\hline$A G$ & 73 & 61 & 3.662 & 0.1603 & 11 & 1.333 & 0.5135 & 12 & 0.954 & 0.6207 \\
\hline GG & 3 & 0 & & & 2 & & & 1 & & \\
\hline A & 287 & 189 & 1.686 & 0.1836 & 41 & 0.117 & 0.7316 & 46 & 0.834 & 0.3538 \\
\hline G & 79 & 61 & & & 15 & & & 14 & & \\
\hline \multicolumn{11}{|l|}{ G857A } \\
\hline GG & 129 & 86 & & & 17 & & & 24 & & \\
\hline $\mathrm{GA}$ & 51 & 33 & 0.986 & 0.6108 & 10 & 3.391 & 0.1835 & 6 & 3.244 & 0.1975 \\
\hline $\mathrm{AA}$ & 3 & 6 & & & 1 & & & 0 & & \\
\hline G & 309 & 205 & 0.419 & 0.524 & 44 & 2.750 & 0.0964 & 54 & 2.013 & 0.1373 \\
\hline A & 57 & 45 & & & 12 & & & 6 & & \\
\hline
\end{tabular}

$\boldsymbol{p}$ : Genotype and allelic $\mathrm{p}$-value for each marker, respectively. $\boldsymbol{p}^{\mathbf{1}}, \boldsymbol{p}^{\mathbf{2}}$ and $\boldsymbol{p}^{\mathbf{3}}$ : Association between Afro-Brazilians $\times$ Whites; Whites $\times$ Amerindians and Amerindians $\times$ Afro-Brazilians, respectively. $\boldsymbol{a}, \boldsymbol{b}$ and $\boldsymbol{c}$ : $p$-value adjusted $\left(10^{3}\right.$ permutations) $=0.06494,0.006993$ and 0.004995 , respectively. $\chi \chi^{2}$ : Chi-square tests. Significant association is indicated in bold. 
Table 3 Logistic regression analysis for risk of NAT2 mutant allele carrier among ethnic groups

\begin{tabular}{ccccccc}
\hline & $\begin{array}{c}\text { Afro-Brazilians } \\
\text { OR (Cl 95\%) }\end{array}$ & $\boldsymbol{p}^{\mathbf{1}}$ & $\begin{array}{c}\text { Whites } \\
\text { OR (Cl 95\%) }\end{array}$ & $\boldsymbol{p}^{\mathbf{2}}$ & $\begin{array}{c}\text { Amerindians } \\
\text { OR (Cl 95\%) }\end{array}$ & $\boldsymbol{p}^{\mathbf{3}}$ \\
\hline $191 \mathrm{~A}$ & $1.81(0.50-6.54)$ & 0.392 & $1.95(0.42-9.08)$ & 0.361 & $0.22(0.28-1.76)$ & 0.0003 \\
\hline $481 T$ & $1.35(0.59-3.06)$ & 0.474 & $0.97(0.33-2.78)$ & 0.651 & $1.50(0.25-8.71)$ & 0.277 \\
\hline $590 \mathrm{~A}$ & $0.33(0.12-0.95)$ & 0.317 & $0.27(0.07-1.03)$ & 0.056 & $3.71(0.28-8.54)$ & 0.040 \\
\hline $803 G$ & $1.52(0.67-3.47)$ & 0.320 & $0.97(0.33-2.82)$ & 0.961 & $1.02(0.35-2.98)$ & 0.356 \\
\hline $857 A$ & $1.73(0.65-4.60)$ & 0.273 & $2.56(0.77-8.51)$ & 0.126 & $0.39(0.05-2.89)$ & 0.003 \\
\hline
\end{tabular}

Reference group is G191, C481, G590, A803 and G857, respectively. Odds Ratio (OR) and 95\% Confidence Interval (CI) for each reference allele compared are shown. $\boldsymbol{p}$ : $\boldsymbol{p}$-value. $\boldsymbol{p}^{\mathbf{1}}, \boldsymbol{p}^{\mathbf{2}}$ and $\boldsymbol{p}^{\mathbf{3}}$. Association between Afro-Brazilians $\times$ Whites; Whites $\times$ Amerindians and Amerindians $\times$ Afro-Brazilians, respectively. Significant association is indicated in bold.

logistic regression analysis $(\mathrm{OR}=3.714 ; 95 \% \mathrm{CI}=0.28$ 8.54; $p=0.040$ ) (Table 3 ). Although homozygous carriers of the $A 803 G$ mutant allele $(G G)$ were not detected in Afro-Brazilian individuals in this study, this genotype was found in the White and Amerindian descendents with a frequency of 6.1 and $3.4 \%$, respectively. Similarly, homozygous carriers of G857A wild allele (AA) were not found in the Amerindian group.

\section{Haplotypic Associations}

The sample was in Hardy-Weinberg equilibrium ( $\mathrm{p}>$ 0.05 ) for the five SNPs (Table 4), as well as separately by ethnicity (data not shown). NAT2 SNP combinations were inferred from haplotype data. Linkage disequilibrium (LD) analysis in the general population revealed that the five common NAT2 SNPs had the weak D' as well as some low $\mathrm{r}^{2}$ values. Haplotype blocks were constructed if D' between SNPs was 1.0. Using this criterion, significant differences in haplotype structure among the ethnic groups were observed (Figure 1).
Additionally to the haplotype analysis according to LD pattern, another haplotype construction based on acetylator phenotype was performed using the most common NAT2 slow SNPs. Thus, this approach estimates a minimum percentage of slow acetylators and avoids misclassification of NAT2 haplotypes in accordance with official nomenclature. The G191A SNP, which leads to an amino acid change in position 64 of the Nat 2 protein, produces an enzyme with reduced acetylation capacity $[24,25]$. The same functional phenomenon occurs with the $6590 A$ allele. In this context, we estimated that any haplotype comprising at least one of these alleles, $191 \mathrm{~A}$ and $590 \mathrm{~A}$, should be theoretically treated as a slow acetylator. It is worthwhile to observe that the slow acetylator haplotypes are underestimated, since the $857 \mathrm{~A}$ allele may also generate the slow acetylator phenotype (NAT2*7A and NAT2*7B) [26].

Using this criterion, the haplotype distribution is demonstrated in Table 4. For practical purposes, the haplotype distribution was labelled from $\mathrm{A}$ to $\mathrm{L}$ in a

Table 4 NAT2 haplotypes frequency in Brazilian ethnic groups.

\begin{tabular}{|c|c|c|c|c|c|c|c|c|c|c|}
\hline \multicolumn{2}{|r|}{ Haplotype } & \multicolumn{5}{|c|}{ SNPs (HWpval) } & \multicolumn{4}{|c|}{ Haplotypes (n) } \\
\hline & C.N. & $\begin{array}{c}\text { G191A } \\
(0.348)\end{array}$ & $\begin{array}{c}C 481 T \\
(0.613)\end{array}$ & $\begin{array}{c}\text { G590A } \\
(1.0)\end{array}$ & $\begin{array}{l}A 803 G \\
(0.303)\end{array}$ & $\begin{array}{c}G 857 A \\
(0.524)\end{array}$ & Total & Afro-Brazilians & Whites & Amerindians \\
\hline$A$ & $(N A T 2 * 4)$ & G & C & G & $A$ & G & 45 & 33 & 9 & 6 \\
\hline $\mathrm{B}$ & $\left(N A T 2^{*} \mathrm{C}\right)$ & G & $\mathrm{T}$ & G & G & G & 35 & 6 & 4 & 3 \\
\hline$C^{*}$ & $\left(N A T 2 * 6 A{ }^{*} 6 B\right)$ & G & C & $A$ & A & G & 23 & 3 & 1 & 7 \\
\hline$D$ & $\left(N^{\prime} T_{2}^{*} 11 A^{*} 11 B\right)$ & G & $\mathrm{T}$ & G & $A$ & G & 23 & 5 & 2 & 2 \\
\hline$E$ & (NAT2*6I/6J) & G & $\mathrm{C}$ & $A$ & $A$ & A & 11 & 2 & 1 & - \\
\hline $\mathrm{F}$ & $\left(N A T 2 * 7 A{ }^{*} 7 B\right)$ & G & C & G & A & A & 9 & 1 & 3 & - \\
\hline $\mathrm{G}$ & $\left(N A T 2 * 14 A{ }^{*} 14 B /{ }^{*} 14 H\right)$ & A & C & G & A & G & 8 & 1 & 1 & - \\
\hline $\mathrm{H}$ & $\left(N A T 2^{*} 12\right)$ & G & C & G & G & G & 6 & 1 & 1 & - \\
\hline$I^{* *}$ & $(N A T 2 * 6 E)$ & G & $\mathrm{T}$ & A & A & G & 5 & - & - & 3 \\
\hline$J$ & (n.ds.) & G & $\mathrm{T}$ & G & A & A & 4 & 1 & - & 0 \\
\hline K & $($ NAT2*12C+857A) & G & $\mathrm{T}$ & G & G & $A$ & 4 & 1 & - & 1 \\
\hline $\mathrm{L}$ & $(N A T 2 * 14 C / * 14 I)$ & A & $\mathrm{T}$ & G & A & G & 3 & - & 1 & - \\
\hline \multicolumn{2}{|c|}{ Slow Acetylator Haplotype } & A & $\mathrm{N}$ & A & $\mathrm{N}$ & $\mathrm{N}$ & 50 & $29^{+}$ & $6^{+}$ & $11^{+}$ \\
\hline
\end{tabular}

HWpval: Hardy-Weinberg equilibrium $p$-value for the whole sample. ${ }^{*}$ and ${ }^{*}$ significant difference in frequency between Amerindians and Afro-Brazilians $\left(\chi \chi^{2}\right.$ : $6.517 ; p=0.0107$ and $\chi x^{2}: 5.539 ; p=0.0186$, respectively). C, E, G, I and L are slow acetylator haplotypes and are indicated in bold. ' - ': Absent or with frequency $<1 \%$. 'N': any nucleotide. ' + ': haplotypes with frequencies < $1 \%$ are included. C.N.: Consensus Human Arylamine N-Acetyltransferase Gene Nomenclature -http:// louisville.edu/medschool/pharmacology/consensus-human-arylamine-n-acetyltransferase-gene-nomenclature; (n.d.s): SNP combination not described. 
A Afro-Brazilians

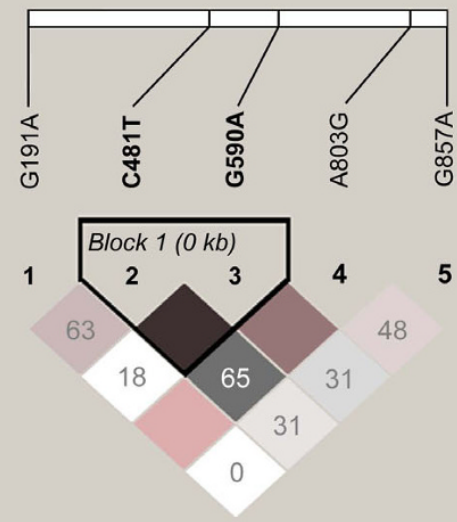

Block 1: $D^{\prime}=1.0$

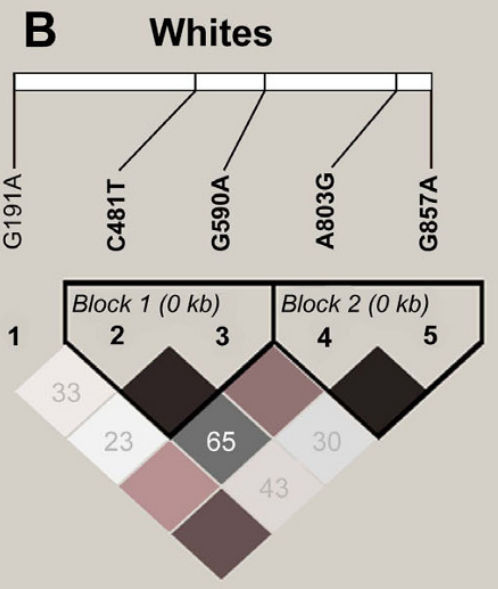

Block 1: $D^{\prime}=1.0$

\section{Amerindians}

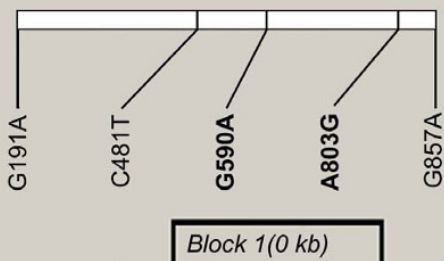

1

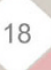

2

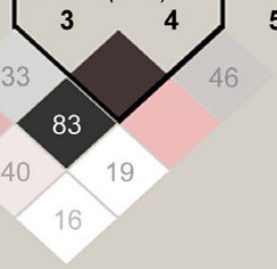

Block 1 and 2: $D^{\prime}=1.0$

Figure 1 LD block structure across NAT2 gene. The upper panel shows the location of 5 polymorphisms in NAT2 gene and lower panel shows the output of Haploview. LD plot where in each square (with D' values written within the box) represent a pairwise linkage

disequilibrium relationship between the two SNPS. Squares indicate statistically significant LD between the pair of SNPS as measured by the D' statistic. Darker colours of grey indicate higher values of $D^{\prime}$, up to a maximum of 1 and white squares indicate pairwise $D^{\prime}$ values of <1 with no statistically significant evidence of LD. The blocks generated under confidence interval algorithm of Haploview are marked. A: Afro-Brazilians, B: Whites and C: Amerindians.

sliding scale, correspondent to and in accordance with the human NAT2 nomenclature. Five slow acetylator haplotypes were found (C, E, I, J, and L), which were higher in Amerindians (44.9\%) than in Afro-Brazilians and Whites (22.9\% and $25.8 \%$, respectively) (Table 4 ). Interestingly, we found some haplotypes in Amerindians that were not found in the other groups (data not shown). The most frequent haplotype among Afro-Brazilians and Whites was "A" (26.1 and 35.3\%, respectively), whereas $\mathrm{C}$ was the most frequent haplotype among Amerindians (28.6\%). Among all haplotypes, only the distribution of "C" and "I" was statistically different between Amerindians and Afro-Brazilians ( $\mathrm{p}=$ 0.0107 and $p=0.0186$, respectively) (Table 4 ). These two haplotypes are correspondent to $N A T 2 * 6$ haplotype subgroups, ("C" = NAT2*6B; "I" = NAT2 *6E).

\section{Discussion}

Ethnicity is an important variable that influences an individual's health in several ways, in particular increasing risks for the development of chronic diseases and unresponsiveness or adverse reactions to drug treatment [27]. The influence of the ethnic component in the distribution of NAT2 genetic polymorphism is well established. An example is the ethnic-specific $191 A$ allele, mainly identified in Africans (7-20\%) and with lower frequencies in Euro-Caucasian groups (less than 2\%) [28-31]. Another example is the $857 A$ allele, mainly identified in eastern Asians [32].
Following our initial purpose of investigating the frequency of NAT2 SNPs in a Brazilian admixed population, the five most common NAT2 SNPs known from published research were selected. Except for C481T SNP, which does not alter the Nat2 enzymatic function, the other four SNPs are associated with slow acetylator status and had high frequencies in our whole sample as well as among ethnic groups (Table 1 and 2). Although the $191 \mathrm{~A}$ allele has been described as relatively common in African populations but not in Caucasians, no significant difference was observed between both groups in this study (Table 2). Similar results were obtained for G590A. The ethnic similarity in the distribution of NAT2 SNPs observed in this study could be due to the high degree of admixture between Afro-descendents and Euro-Caucasian groups (mainly Portuguese settlers) that has occurred in Brazil over the centuries since colonization [33]. However, the bias from the self-reported ancestry classification method can not be totally excluded.

Interestingly, meaningful results from the distribution of NAT2 alleles in Amerindian descendents were observed. The $590 \mathrm{~A}$ allele was significantly more frequent in Amerindians (42.5\%) than in White or AfroBrazilian descendents (19.4\% and $20.0 \%$, respectively), even after permutation tests to decrease the risk of a type I error (Table 2). Multiple logistic regression analysis confirmed that Amerindians have the highest frequency of the $590 A$ allele with OR (odds ratio) of 3.714 
(95\% confidence interval $-\mathrm{CI}=0.284-8.545 ; p=0.040$ ) (Table 3). Significant difference in the distribution of the $191 \mathrm{~A}$ allele between Amerindians and other groups was revealed by multiple logistic regression analysis, but not in UNPHASED association. The difference in results may be attributed to the small sample size of $191 \mathrm{~A}$ carriers among Amerindians. Moreover, the frequency of the $590 \mathrm{~A}$ allele in Amerindians is higher than what has been reported in studies with Amerindians from Panama (0\% and 3.7\% in Ngawbe and Embera Amerindians, respectively) $[17,34]$. Such unexpected frequency may have originated by phylogeographical differences among Amerindians populations in South-America, miscegenation, and genetic drift.

Despite Fuselli et al. (2007) having found that the NAT2 variants are homogeneously distributed across native populations, the Amerindian sample studied here showed a lower frequency of the $857 A$ allele $(10.3 \%$; OR $=0.391 ; \mathrm{CI}=0.053-2.898 ; p=0.003)$ than those observed in two other Amerindians groups (23.3\% and 22.8\%) [35] (Table 3). To date, the frequency of the $857 \mathrm{~A}$ allele observed in this study is similar to Asian and Central America Amerindian populations [17], which corroborates the hypothesis that native Americans descend from people who migrated from Siberia thousands of years ago and therefore share their genetic background [36,37].

To elicit further information about the relationship of SNPs, a haplotype analysis was performed. Although previous studies have shown the efficiency of the PHASE method, we relied on the work of Sabbagh and Darlu (2005), which shows the effectiveness of the EM method for NAT2 haplotype reconstruction and suggests that there is no impact on phenotype prediction compared to results given by PHASE analysis [38]. We observed significant differences in the haplotype structure and frequency among the descendents of the three ethnic groups (Figure 1 and Table 4). Using haplotype analysis based on LD data, a haplotype block between G590A-A803G (Block 1; Figure $1 C$ ) was detected in Amerindians but was not found in the other two ethnic groups. This result may help to explain the highest frequency of slow acetylation haplotypes in Amerindians (Table 4). Consistent with the hypothesis that Amerindians may not be under a high selective pressure for fast metabolism, we have previously reported different distribution patterns of GSTP1 low activity polymorphism in this same Amerindian population [39]. Different distributions found in Amerindians, when compared with other groups, may be attributed to their low degree of admixture despite the high degree of miscegenation in the whole population. This occurs for historical reasons related to the particular way Brazil was colonized. In this way, the Amerindian group still maintains its socio-economic distinction that contributes to low degrees of admixture.
Due to our limited sample size, we suggest a careful matching of ethnicity for future larger genetic investigations. Except among the Amerindian descendents, our results suggest that self reported ethnicity might not have significant effects on the distribution of these NAT2 genetic variants studied in the Brazilian population. This data is relevant due to the classic role of Nat2 on isoniazid metabolism in tuberculosis treatment, which still remains an important problem of public health. In fact, several reports indicate that the acetylator status is associated with drug-induced hepatitis and Mycobacterium-resistance [40,41]. Furthermore, as observed in other phase II metabolizing enzyme polymorphisms, NAT2 genetic variants have been used as a genetic marker in different diseases like bladder and colon-rectal cancers (fast acetylator and slow acetylator, respectively) $[42,43]$.

\section{Conclusions}

Information gathered on the distribution of genetic polymorphism in populations of different ethnic origins remains essential to understand the interethnic differences in drug disposition and disease risk. This study demonstrates that common distributions of NAT2 SNPs are related with ethnic background in a Brazilian admixed population. Hereafter, DNA sequencing for the entire intron-exon organization of the NAT2 gene will provide more detailed information about genetic diversity and structure in this population. All these findings offer new insights for the investigation of possible nondescribed NAT2 gene-environment effects in admixed populations.

\section{Acknowledgements}

The authors would like to thank Naide Silveira de Souza for helping with the samples and J. Neil Simonsen (Public Health Agency of Canada) for reviewing the manuscript, and Conselho Nacional de Desenvolvimento Científico e Tecnologico (CNPq) and Fundação de Amparo à Pesquisa do Estado da Bahia (FAPESB) for financial support.

\section{Author details}

'Universidade Estadual de Santa Cruz, Laboratório de Farmacogenômica e Epidemiologia Molecular (LAFEM), Ilhéus, Bahia, Brazil. ${ }^{2}$ INCT de Medicina Molecular, Faculdade de Medicina, Universidade Federal de Minas Gerais, Brazil.

\section{Authors' contributions}

LAVM, PRSM, GDP, and FRS designed the study. LAVM selected the subjects, collected the samples, isolated DNA, and carried out statistical analysis. JT and CVNS genotyped the samples. All authors contributed to the writing of the manuscript.

Received: 9 May 2010 Accepted: 5 October 2010

Published: 5 October 2010

\section{References}

1. Nebert DW: Polymorphisms in drug-metabolizing enzymes: what is their clinical relevance and why do they exist? Am J Hum Genet 1997, 60:265-271. 
2. Wilkinson GR: Drug metabolism and variability among patients in drug response. N Engl J Med 2005, 352:2211-2221.

3. Meyer UA: Polymorphism of human acetyltransferases. Environ Health Prospect 1994, 102(Suppl 6):213-216.

4. Riddle B, Jencks WP: Acetyl-coenzyme A: arylamine N-acetyltransferase. Role of the acetyl-enzyme intermediate and the effects of substituent on the rate. J Biol Chem 1971, 246:3250-3258.

5. Hein DW: Molecular genetics and function of NAT1 and NAT2: role in aromatic amine metabolism and carcinogenesis. Mutat Res 2002, 506507:65-77.

6. Ohno M, Yamaguchi I, Yamamoto I, Fukuda T, Yokota S, Maekura R, Ito M, Yamamoto Y, Ogura T, Maeda K, Komuta K, Igarashi T, Azuma J: Slow Nacetyltransferase 2 genotype affects the incidence of isoniazid and rifampicin-induced hepatotoxicity. Int J Tuberc Lung Dis 2000, 4:256-261.

7. Palamanda JR, Hickman D, Ward A, Sim E, Romkes-Sparks M, Unadkat JD: Dapsone acetylation by human liver arylamine $\mathrm{N}$-acetyltransferases and interaction with ant opportunistic infection drugs. Drug Metab Dispos 1995, 23:473-477.

8. Blum M, Grant DM, McBride W, Heim M, Meyer UA: Human Nacetyltransferase genes: isolation, chromosomal localization and functional expression. DNA Cell Biol 1990, 9:193-203.

9. Hickman D, Pope J, Patil SD, Fakis G, Smelt V, Stanley LA, Payton M, Unadkat JD, Sim E: Expression of arylamine $\mathrm{N}$-acetyltransferase in human intestine. Gut 1998, 42:402-409.

10. Windmill KF, McKinnon RA, Zhu XY, Gaedigk A, Grant DM, McManus ME: The role of xenobiotic metabolizing enzymes in arylamine toxicity and carcinogenesis: functional and localization studies. Mutat Res 1997, 376:153-160.

11. Evans DA, Manley KA, Mc KV: Genetic control of isoniazid metabolism in man. Br Med J 1960, 2:485-491.

12. Boukouvala S, Sim E: Structural analysis of the genes for human arylamine $\mathrm{N}$-acetyltransferases and characterization of alternative transcripts. Basic Clin Pharmacol Toxicol 2005, 96:343-351.

13. Furet Y, Bechtel Y, Le Guellec C, Bechtel PR, Autret-Leca E, Paintaud G Clinical relevance of $\mathrm{N}$-acetyltransferase type 2 (NAT2) genetic polymorphism. Therapy 2002, 57:427-431.

14. Spielberg SP: N-acetyltransferases: Pharmacogenetics and clinical consequences of polymorphic drug metabolism. J Pharmacokinet Biopharm 1996, 24:509-519.

15. Norton JT, Witschi MA, Luong L, Kawamura A, Ghosh S, Stack MS, Sim E, Avram MJ, Appella DH, Huang S: Synthesis and anticancer activities of 6amino amonafide derivatives. Anticancer Drugs 2008, 19:23-36.

16. Wood AJ: Racial differences in the response to drugs-pointers to genetic differences. N Engl J Med 2001, 344:1394-1396.

17. Sabbagh A, Langaney A, Darlu P, Gerard N, Krishnamoorthy R, Poloni ES: Worldwide distribution of NAT2 diversity: implications for NAT2 evolutionary history. BMC Genet 2008, 9:21

18. Alves-Silva J, da Silva Santos M, Guimarães PE, Ferreira AC, Bandelt HJ, Pena SD, Prado VF: The ancestry of Brazilian mtDNA lineages. Am J Hum Genet 2000, 67:444-461.

19. Carvalho-Silva DR, Santos FR, Rocha J, Pena SD: The phylogeography of Brazilian Y-chromosome lineages. Am J Hum Genet 2001, 68:281-286.

20. Parra FC, Amado RC, Lambertucci JR, Rocha J, Antunes CM, Pena SD: Color and genomic ancestry in Brazilians. Proc Natl Acad Sci USA 2003, 100:177-182.

21. Doll MA, Fretland AJ, Deitz AC, Hein DW: Determination of Human NAT2 Acetylator Genotype by Restriction Fragment-Length Polymorphism and Allele-Specific Amplification. Anal Biochem 1995, 231:413-420.

22. Dudbridge F: Pedigree disequilibrium tests for multilocus haplotypes. Genet Epidemiol 2003, 25:115-121.

23. Barrett JC, Fry B, Maller J, Daly MJ: Haploview: analysis and visualization of LD and haplotype maps. Bioinformatics 2005, 21:263-265.

24. Rodrigues-Lima F, et al: $3 \mathrm{D}$ model of human arylamine $\mathrm{N}$ acetyltransferase 2: structural basis of the slow acetylator phenotype of the R64Q variant and analysis of the active-site loop. Biochem Biophys Res Commun 2003, 291:116-123.

25. Walraven JM, Zang Y, Trent JO, Hein DW: Structure/function evaluations of single nucleotide polymorphisms in human n-acetyltransferase 2. Curr Drug Metab 2008, 9:471-486.
26. Zang Y, Doll MA, Zhao S, States JC, Hein DW: Functional characterization of single nucleotide polymorphisms and haplotypes of human $\mathrm{N}$ acetyltransferase 2. Carcinogenesis 2007, 28:1665-1671.

27. Au WW, Sierra-Torres CH, Cajas-Salazar N, Salama SA: Inheritance of polymorphic metabolizing genes on environmental disease and quality of life. Mutat Res 1999, 428:131-140

28. Delomenie C, Sica L, Grant DM, Krishnamoorthy R, Dupret JM: Genotyping of the polymorphic N-acetyltransferase (NAT2*) gene locus in two native African populations. Pharmacogenetics 1996, 6:177-185.

29. Patin E, Harmant C, Kidd KK, Kidd J, Froment A, Mehdi SQ, Sica L, Heyer E, Quintana-Murci L: Sub-Saharan African coding sequence variation and haplotype diversity at the NAT2 gene. Hum Mutat 2006, 27:720.

30. Cascorbi I, Drakoulis N, Brockmoller J, Maurer A, Sperling K, Roots I: Arylamine $\mathrm{N}$-acetyltransferase (NAT2) mutations and their allelic linkage in unrelated Caucasian individuals: correlation with phenotypic activity. Am J Hum Genet 1995, 57:581-592.

31. Agundez JA, Olivera M, Martinez C, Ladero JM, Benitez J: Identification and prevalence study of 17 allelic variants of the human NAT2 gene in a white population. Pharmacogenetics 1996, 6:423-428.

32. Lin $\mathrm{HJ}$, Han CY, Lin BK, Hardy S: Slow acetylator mutations in the human polymorphic $\mathrm{N}$-acetyltransferase gene in 786 Asians, blacks, Hispanics, and whites: application to metabolic epidemiology. Am J Hum Genet 1993, 52:827-834.

33. Teixeira RL, Miranda AB, Pacheco AG, Lopes MQ, Fonseca-Costa J, Rabahi MF, Melo HM, Kritski AL, Mello FC, Suffys PN, Santos AR: Genetic profile of the arylamine $\mathrm{N}$-acetyltransferase 2 coding gene among individuals from two different regions of Brazil. Mutat Res 2007, 624:31-40.

34. Jorge-Nebert LF, Eichelbaum M, Griese EU, Inaba T, Arias TD: Analysis of six SNPs of NAT2 in Ngawbe and Embera Amerindians of Panama and determination of the Embera acetylation phenotype using caffeine. Pharmacogenetics 2002, 12:39-48.

35. Fuselli S, Gilman RH, Chanock SJ, Bonatto SL, De Stefano G, Evans CA, Labuda D, Luiselli D, Salzano FM, Soto G, Vallejo G, Sajantila A, Pettener D, Tarazona-Santos E: Analysis of nucleotide diversity of NAT2 coding region reveals homogeneity across Native American populations and high intra-population diversity. Pharmacogenomics J 2007, 7:144-152.

36. Santos FR, Pandya A, Tyler-Smith C, Pena SD, Schanfield M, Leonard WR, Osipova L, Crawford MH, Mitchell RJ: The central Siberian origin for native American Y chromosomes. Am J Hum Genet 1999, 64:619-628.

37. Lell JT, Sukernik RI, Starikovskaya YB, Su B, Jin L, Schurr TG, Underhill PA, Wallace DC: The dual origin and Siberian affinities of Native American $Y$ chromosomes. Am J Hum Genet 2002, 70:192-206.

38. Sabbagh A, Darlu P: Inferring haplotypes at the NAT2 locus: the computational approach. BMC Genet 2005, 6:30

39. Magno LA, Talbot J, Talbot T, Borges Santos AM, Souza RP, Marin LJ, Moreli ML, de Melo PR, Correa RX, Rios Santos F, Di Pietro G: Glutathione stransferase variants in a brazilian population. Pharmacology 2009, 83:231-236.

40. Possuelo LG, Castelan JA, de Brito TC, Ribeiro AW, Cafrune PI, Picon PD, Santos AR, Teixeira RL, Gregianini TS, Hutz MH, Rossetti ML, Zaha A: Association of slow $\mathrm{N}$-acetyltransferase 2 profile and anti-TB druginduced hepatotoxicity in patients from Southern Brazil. Eur J Clin Pharmacol 2008, 64:673-681.

41. Ohno M, Yamaguchi I, Yamamoto I, Fukuda T, Yokota S, Maekura R, Ito M, Yamamoto Y, Ogura T, Maeda K, Komuta K, Igarashi T, Azuma J: Slow Nacetyltransferase 2 genotype affects the incidence of isoniazid and rifampicin-induced hepatotoxicity. Int I Tuberc Lung Dis 2000, 4:256-261.

42. Agundez JA: Polymorphisms of human n-acetyltransferases and cancer risk. Curr Drug Metab 2008, 9:520-531.

43. Di Pietro G, Magno LA, Rios-Santos F: Glutathione S-transferases: an overview in cancer research. Expert Opin Drug Metab Toxicol 2010, 6:153-170.

doi:10.1186/1471-2156-11-87

Cite this article as: Talbot et al: Interethnic diversity of NAT2

polymorphisms in Brazilian admixed populations. BMC Genetics 2010 11:87. 